\title{
Seeing ophthalmologic problems in Parkinson disease
}

\section{Results of a visual impairment questionnaire}

Carlijn D.J.M. Borm, MD, * Femke Visser, MD,* Mario Werkmann, MD, Debbie de Graaf, MSc, Diana Putz, MD, Klaus Seppi, MD, Werner Poewe, MD, Annemarie M.M. Vlaar, MD, PhD, Carel Hoyng, MD, PhD,

Bastiaan R. Bloem, MD, PhD, Thomas Theelen, MD, PhD, and Nienke M. de Vries, PhD

Neurology ${ }^{\circledR}$ 2020;94:e1539-e1547. doi:10.1212/WNL.0000000000009214

\section{Abstract}

\section{Objective}

To determine the prevalence and clinical effect of ophthalmologic symptoms in patients with Parkinson disease (PD), compared with controls, using a standardized questionnaire.

\section{Methods}

In this observational, cross-sectional, multicenter study, 848 patients with PD and 250 healthy controls completed the Visual Impairment in Parkinson's Disease Questionnaire (VIPD-Q). The VIPD-Q addressed 4 domains according to structures: (1) ocular surface; (2) intraocular; (3) oculomotor; and (4) optic nerve. The questionnaire also assessed the effect of ophthalmologic symptoms on daily activities.

\section{Results}

One or more ophthalmologic symptoms were reported by $82 \%$ (95\% confidence interval [CI], $80-85$ ) of patients, compared with $48 \%$ (95\% CI, 42-54) of controls $(p<0.001)$. Patients with PD experienced more ophthalmologic symptoms across all domains than controls $(p<0.001)$, as reflected by a higher VIPD-Q total score among patients (median 10 [interquartile range (IQR) 13]) than controls (median 2 [IQR 5]; $p<0.001$ ). Ophthalmologic symptoms interfered with daily activities in $68 \%$ (95\% CI, 65-71) of patients, compared with $35 \%$ (95\% CI, 29-41) of controls $(p<0.001)$.

\section{Conclusion}

Patients with PD have a higher prevalence of ophthalmologic symptoms than controls. Moreover, these frequently interfere with daily activities. A screening questionnaire such as the VIPD-Q may help with identifying ophthalmologic symptoms in PD, thereby enabling more timely treatment.
Correspondence Dr. Borm carlijn.borm@ radboudumc.nl 


\section{Glossary}

$\mathbf{C I}=$ confidence interval; $\mathbf{I Q R}=$ interquartile range; $\mathbf{L E D}=$ levodopa equivalent dose; $\mathbf{O L V G}=$ Onze Lieve Vrouwe Gasthuis; PD = Parkinson disease; VIPD-Q = Visual Impairment in Parkinson's Disease Questionnaire.

Ophthalmologic symptoms are underreported by patients with Parkinson disease (PD) and often overlooked by their treating physicians. ${ }^{1}$ The most commonly reported ophthalmologic symptoms include double vision, blurry vision, watery eyes, and visual hallucinations. ${ }^{1}$ In PD, retinal dopamine depletion and decreased dopaminergic innervation of the visual cortex can lead to various visual problems, including impairments of oculomotor control, contrast sensitivity, color vision, and visuospatial construction. ${ }^{2}$ Also, patients with PD have an increased risk of seborrheic blepharitis and keratoconjunctivitis sicca (dry eyes). ${ }^{3}$ As almost $80 \%$ of visual impairments worldwide are treatable or preventable, timely recognition is pivotal. ${ }^{4}$ This is highlighted by the clinical effect of ophthalmologic symptoms in the general population, ${ }^{5,6}$ which may lead to social isolation and a reduced quality of life. ${ }^{5,6}$ Importantly, intact vision is especially vital for patients with PD to compensate (through visual guidance) for their common loss of motor automaticity that is caused by basal ganglia dysfunction. ${ }^{7}$ The potential effect is emphasized by the fact that ophthalmologic disorders combined with postural and gait instability increase the risk of falls and fallrelated injuries. ${ }^{7,8}$ Despite this, there are few pioneering studies in this field, with relatively small sample sizes $(\mathrm{n}=$ 10-100), and these only evaluated a limited number of ophthalmologic symptoms in PD. ${ }^{3,9-12}$ Little is known about the extent and frequency of ophthalmologic symptoms and their effect on daily life activities in patients with PD. Here, we aim to systematically determine the prevalence of a wide range of ophthalmologic symptoms in a large sample of patients with PD compared with controls, and to explore the effect of these ophthalmologic symptoms on daily life functioning.

\section{Methods}

\section{Study design}

This multicenter, cross-sectional study is part of a larger study on visual impairments in PD. The protocol has been published previously. ${ }^{13}$ We used a newly developed screening questionnaire - the Visual Impairment in Parkinson's Disease Questionnaire (VIPD-Q) - to gain insight into the prevalence and clinical effect of ophthalmologic symptoms in patients with PD. The questionnaire was sent out by 3 study centers, 2 university hospitals (Radboudumc Nijmegen, the Netherlands; and the Medical University Innsbruck, Austria), and 1 general hospital (Onze Lieve Vrouwe Gasthuis [OLVG], Amsterdam, the Netherlands) between December 2016 and July 2018. Each center obtained local ethical approval. This study was performed in accordance with the Declaration of Helsinki. All respondents participated anonymously and voluntarily.

\section{Samples}

We used multiple methods to recruit patients. At Radboudumc, an open Web link was circulated by email to a panel of patients with PD interested in research $(\mathrm{n}=350)$ and in the outpatient clinic. The questionnaire was sent by mail to all patients treated for PD in OLVG $(\mathrm{n}=476)$. In Innsbruck, the questionnaire was completed during patient interviews at the outpatient clinic, where all scheduled patients with PD were invited to participate $(\mathrm{n}=300)$. Controls were recruited from partners and acquaintances of patients with PD.

\section{Standard protocol approvals, registrations, and patient consents}

Dutch Trial Registration, NL7421; ethical approval information: NL58535.091.16, Nijmegen, the Netherlands; and AN2016-0181, Innsbruck, Austria.

\section{Measures}

The VIPD-Q was developed by neurologists and ophthalmologists to detect a broad range of ophthalmologic disorders, and was based on extensive literature study, other questionnaires, and common and disabling ophthalmologic disorders in patients with PD and healthy older people. $^{1,3,9,11,14-25}$

The original questionnaire included 22 questions on ophthalmologic symptoms. This number of items was reduced to 17 after a revision round that aimed to improve readability and face validity. The questionnaire also includes a standard set of demographic questions. We categorized the VIPD-Q into 4 domains of ophthalmologic disorders, according to ocular structures: (1) ocular surface; (2) intraocular; (3) oculomotor; and (4) optic nerve. Each domain consists of 4 questions. There is 1 question on visual hallucinations. The questions of the VIPD- $Q$ can be found in table 1 and the questionnaire is described in more detail in a former publication. ${ }^{13}$ Answers were given on a 4-point Likert scale ranging from "never have symptoms" to "daily symptoms," without an option for a neutral answer.

Outcomes included the prevalence of ophthalmologic symptoms, with presence for each specific question being defined as a score of 2 or higher (i.e., "every week" or "every day"), except for the question on visual hallucinations, where a score of 1 or higher $(\geq$ once/mo) was considered as having visual hallucinations. We calculated the total score of the VIPD-Q (only for complete questionnaires), the score per domain (when all questions relating to a domain were answered), and the scores for individual questions related to a specific ophthalmologic symptom (i.e., double vision, 
Table 1 Prevalence of ophthalmologic symptoms

\begin{tabular}{|c|c|c|c|}
\hline Ophthalmologic symptoms reported weekly or daily & PD, n (\%) & Controls, n (\%) & $p$ Value $^{a}$ \\
\hline \multicolumn{4}{|l|}{ Ocular surface } \\
\hline I have blurry vision when I read or work on a computer. & $385(46)$ & $31(12)$ & $<0.001$ \\
\hline I have a burning sensation or gritty feeling in my eyes. & $231(28)$ & $20(8)$ & $<0.001$ \\
\hline I have mucus/slime or particles in my eyes or eyelids. & $167(20)$ & $14(6)$ & $<0.001$ \\
\hline I have watery eyes. & $261(31)$ & $38(15)$ & $<0.001$ \\
\hline \multicolumn{4}{|l|}{ Intraocular } \\
\hline When I read, some letters disappear. & $168(20)$ & $13(5)$ & $<0.001$ \\
\hline Lines that should be straight appear to be wavy or blurred. & $140(17)$ & $12(5)$ & $<0.001$ \\
\hline I won't go out alone in the evening or at night because my night vision is insufficient. & $134(16)$ & $8(3)$ & $<0.001$ \\
\hline When I drive at night, the oncoming headlights cause more glare than before. & $347(43)$ & $54(23)$ & $<0.001$ \\
\hline \multicolumn{4}{|l|}{ Oculomotor } \\
\hline Quick movements are hard to follow with my eyes. & $205(25)$ & $9(4)$ & $<0.001$ \\
\hline I have double vision. & $186(22)$ & $6(3)$ & $<0.001$ \\
\hline I can read better with one eye closed. & $142(17)$ & $15(6)$ & $<0.001$ \\
\hline I have trouble with depth perception. I find it hard to say which one of 2 objects is closer. & $139(17)$ & $6(2)$ & $<0.001$ \\
\hline \multicolumn{4}{|l|}{ Optic nerve } \\
\hline Colors seem to be paler than before. & $95(11)$ & $7(3)$ & $<0.001$ \\
\hline I can't read plain text on a colored or gray background. & $212(26)$ & $25(10)$ & $<0.001$ \\
\hline I run into objects or people or feel that parts of my visual field are missing. & $77(9)$ & $5(2)$ & $<0.001$ \\
\hline I have problems with rapid changes of light intensity. & $222(27)$ & $26(11)$ & $<0.001$ \\
\hline I see things that other people do not see (hallucinations). & $181(22)$ & $5(2)$ & $<0.001$ \\
\hline
\end{tabular}

Abbreviation: $\mathrm{PD}=$ Parkinson disease.

a $p<0.05$ was considered statistically significant.

hallucinations). The maximum total score is 51 (when all 17 questions are answered with "daily"), and the maximum score per domain is 12 points. The influence of ophthalmologic symptoms on daily activities (i.e., reading, driving a car, working on the computer, watching television, performing hobbies, walking, personal care) was scored with yes or no questions, whether or not the patient experienced problems in that specific activity because of ophthalmologic symptoms. Participants were also asked about the number of falls in the last 6 months. Quality of life was assessed based on the question "Do ophthalmologic symptoms influence your quality of life?" Answer possibilities were "no effect," "moderate effect," or "severe effect."

\section{Statistical analysis}

We compared patients with PD with controls using $\chi^{2}$ tests for categorical values (sex, education, comorbidity, visited ophthalmologist, visual aid, vision changes during the day, difficulties with daily activities, effect on quality of life) and MannWhitney $U$ test for nonparametric continuous variables (age, total VIPD-Q score, score per domain, levodopa equivalent dose $[\mathrm{LED}])$.

To identify the influence of ophthalmologic symptoms on falling, a multiple regression analysis was conducted, with correction for potential confounders (age, sex, LED, and disease duration). A multivariate logistic regression analysis was performed to investigate the association between ophthalmologic symptoms as reflected by the total VIPD-Q score and disease duration, adjusted for sex, age, and LED. For internal consistency, $\omega$ total, Cronbach coefficient $\alpha$, and greater lower bound were calculated. A $p$ value $<0.05$ was considered significant. Statistical analyses were conducted using SPSS 22.0 (SPSS Inc., IBM, Chicago, IL) and SAS (SAS Institute Inc, Cary, NC) statistical software.

\section{Data availability}

Requests for data from the VIP Study will be considered by B.R.B. in line with data protection laws. The general policy is that as long as the proposed use of the data is scientifically 
valid and if ethics approval permits, suitably anonymized data can be shared with other researchers.

\section{Results}

A total of 1,098 participants completed the questionnaire: 848 patients with $\mathrm{PD}$ and 250 age-matched controls (ratio of 3:1). Among patients with PD, 288 participants completed the questionnaire online, 308 by mail, and 252 by interview in the outpatient clinic. We could not calculate the exact response rate for the online completed questionnaires, since it was not possible to determine how many potential respondents visited our online platform, but the invitation to fill out the questionnaire was sent out to 350 patients (of whom 288 completed the questionnaire [82\%]). The response rate was $65 \%(308 / 476)$ by mail and $84 \%(252 / 300)$ by interview. The mean time needed to complete the questionnaire measured online and during interview was 20 minutes.

\section{Participant characteristics}

Table 2 summarizes the baseline characteristics. The 2 groups were well-balanced for education and comorbidity. The median age of the participants was 70 years in both groups, with a slightly higher percentage of men among patients with $\mathrm{PD}$ $(60 \%)$ than controls $(52 \%)\left(F_{1}=4.755, p=0.029\right)$. Patients with PD consulted the ophthalmologist and used visual aids more often than controls. Compared with controls, more patients with $\mathrm{PD}$ experienced visual changes during the day (38\% vs $\left.19 \% ; F_{1}=29.695 ; p<0.001\right)$ and more patients with PD stated that their visual aid was not working properly $(28 \%$ vs $\left.17 \% ; F_{1}=11.277 ; p=0.001\right)$. As expected, the use of a walking aid when walking outdoors was significantly higher among patients with PD (37\%) than controls (7\%) $\left(F_{1}=81.46 ; p<0.001\right)$.

\section{Prevalence of ophthalmologic symptoms}

Among patients with PD, one or more ophthalmologic symptoms were present in $82 \%$ (95\% confidence interval [CI], 80-85), compared with $48 \%$ (95\% CI, 42-54) of the controls $\left(F_{1}=118.53 ; p<0.001\right)$. Table 1 provides the percentages of ophthalmologic symptoms reported per question for both groups. Some ophthalmologic symptoms were found almost exclusively in PD (e.g., seeing colors less brightly, double vision, difficulty with depth perception, visual hallucinations), whereas others were also common in controls (e.g., watery eyes, light sensitivity, and glare at night). However, all ophthalmologic symptoms were significantly more prevalent in patients than in controls.

Patients with PD experienced more ophthalmologic symptoms simultaneously than controls, as reflected by the median total score on the VIPD-Q (PD: median score 10 [interquartile range (IQR) 13, range 0-48]; controls: median score 2 [IQR 5], range 0-30; Mann-Whitney $U=38,781$; $\left.\mathrm{n}_{1}=\mathrm{n}_{2}=997 ; p<0.001\right)$, shown in figure 1 . Total scores did
Table 2 Participant characteristics

\begin{tabular}{|c|c|c|c|}
\hline & $\begin{array}{l}\text { PD } \\
(n=848)\end{array}$ & $\begin{array}{l}\text { Controls } \\
(n=250)\end{array}$ & $\begin{array}{l}p \\
\text { Value }^{a}\end{array}$ \\
\hline Men, n (\%) & $467(60)$ & $125(52)$ & 0.029 \\
\hline Age, y, median (IQR) [range] & $\begin{array}{l}70(12.5) \\
{[33-93]}\end{array}$ & $\begin{array}{l}70(13.8) \\
{[31-94]}\end{array}$ & NS \\
\hline $\begin{array}{l}\text { Disease duration, y, median } \\
\text { (IQR) [range] }\end{array}$ & $\begin{array}{l}7(7.0) \\
{[1-39]}\end{array}$ & NA & NA \\
\hline $\begin{array}{l}\text { Levodopa dose equivalent, mg, } \\
\text { median (IQR) [range] }\end{array}$ & $\begin{array}{l}579(757) \\
{[0-2,147]}\end{array}$ & NA & NA \\
\hline Education, college degree, n (\%) & $272(32)$ & $94(38)$ & NS \\
\hline $\begin{array}{l}\text { Country of birth (within } \\
\text { Europe), } \mathrm{n}(\%)\end{array}$ & $803(96)$ & $235(96)$ & NS \\
\hline Comorbidity, n (\%) & $427(52)$ & $96(44)$ & NS \\
\hline Diabetes mellitus & $83(11)$ & $33(13)$ & NS \\
\hline Hypertension & $179(23)$ & $53(21)$ & NS \\
\hline Stroke & $26(3)$ & $6(2)$ & NS \\
\hline COPD & $33(4)$ & $6(2)$ & NS \\
\hline Migraine & $15(2)$ & $4(2)$ & NS \\
\hline History of cataract & $227(27)$ & $56(23)$ & NS \\
\hline Visited ophthalmologist, n (\%) & $286(35)$ & $45(19)$ & $<0.001$ \\
\hline Uses visual aid, $\mathbf{n}(\%)$ & $745(95)$ & $215(88)$ & 0.001 \\
\hline Visual aid works properly, n (\%) & $569(72)$ & $195(83)$ & 0.001 \\
\hline $\begin{array}{l}\text { Using a walking aid outside, } \\
\text { n (\%) }\end{array}$ & 309 (37) & $17(7)$ & $<0.001$ \\
\hline $\begin{array}{l}\text { Vision changes during the day, } \\
\text { n (\%) }\end{array}$ & $310(38)$ & 45 (19) & $<0.001$ \\
\hline Falls present (last 6 months) & $266(32)$ & $24(10)$ & $<0.001$ \\
\hline
\end{tabular}

Abbreviations: $\mathrm{COPD}=$ chronic obstructive pulmonary disease; $\mathrm{IQR}=$ interquartile range; NA = not applicable; NS = not significant; PD = Parkinson disease.

a $p<0.05$ was considered statistically significant.

not differ between men and women with PD $\left(F_{1}=0.238\right.$; $p=0.780)$. Among controls, women had significantly higher scores than men $\left(F_{1}=7.223 ; p=0.007\right)$. Figure 2 shows the number of ophthalmologic symptoms per domain for both groups. Symptoms related to the ocular surface were most common among patients (PD: $63 \%$; controls: $24 \% ; \chi^{2}[1, \mathrm{n}=$ $1,081]=120.73 ; p<0.001)$, followed by symptoms in the intraocular domain (PD: $54 \%$; controls: $25 \%$; $p<0.001$ ), then oculomotor domain (PD: 44\%; controls: $10 \% ; p<0.001$ ) and optic nerve domain (PD: 44\%; controls: 19\%; $p<0.001$ ). The prevalence of visual hallucinations was $22 \%$ among patients with PD compared with only $2 \%$ among controls $(p<0.001)$. Patients with PD who participated through the open Web link had a slightly higher prevalence of ophthalmologic symptoms (87\%) and a higher median total score on the VIPD-Q (score 13) than patients who participated by mail ( $81 \%$; score 9$)$ or by interview (79\%; score 8 ). 
Figure 1 Boxplot of the total Visual Impairment in Parkinson's Disease Questionnaire (VIPD-Q) score

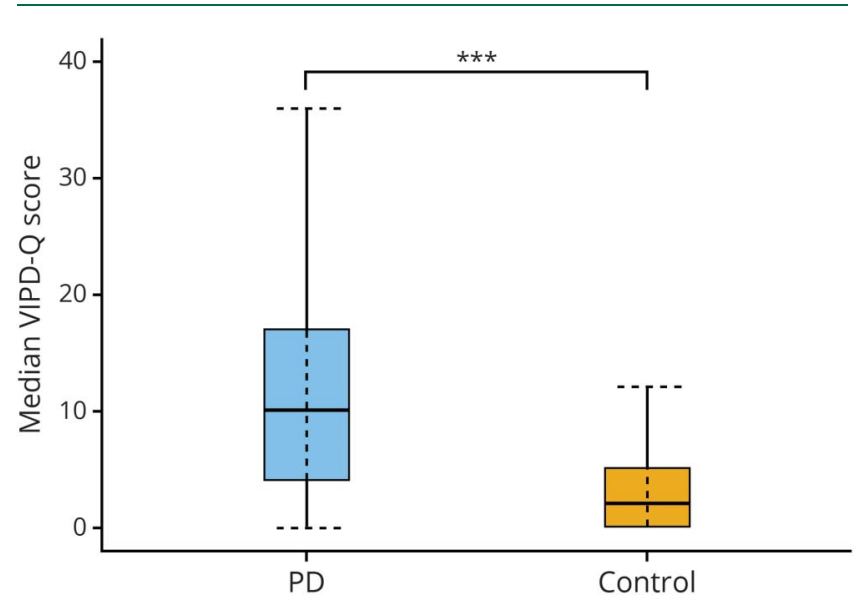

Boxplot of the median total score of the VIPD-Q in Parkinson disease (PD) and the control group ( $n=773$, PD group; $n=224$, control group) $\star \star \star p<0.05$.

\section{Effect on daily activities}

Figure 3 shows that patients with PD indicated more difficulties with daily activities due to ophthalmologic symptoms than controls $\left(\chi^{2}[1, \mathrm{n}=1,097]=86.22 ; p<0.001\right)$. Patients experienced the greatest interference of ophthalmologic symptoms when reading (52\%), followed by driving a car (33\%), watching television (28\%), and working on the computer (28\%). Participants with PD fell more frequently than controls (PD: 4\% daily or weekly, $28 \%$ once or twice a month; controls: $0 \%$ daily or weekly, $12 \%$ once or twice a month; $p<0.001$ ). The frequency of falls increased with a higher score on the VIPD-Q in both groups. A multivariate logistic regression showed that falling was related to higher VIPD-Q total scores (odds ratio, 1.043; 95\% CI, 1.03-1.06; $p<0.001, r=0.049$ ) after correction for age, disease duration, LED, and sex. We found a weak, but significant, correlation between the VIPD-Q total score and disease duration (Pearson correlation $r=0.18, p<0.001$ ). Furthermore, 53\% (95\% CI, 49-56) of patients with PD reported a moderate to severe effect of ophthalmologic symptoms on their quality of life, compared with $16 \%$ (95\% CI, $12-21)$ of controls $\left(F_{2}=97.17, p<0.001\right)$.

Figure 2 Number of ophthalmologic symptoms reported per domain compared between patients with Parkinson disease (PD) and controls

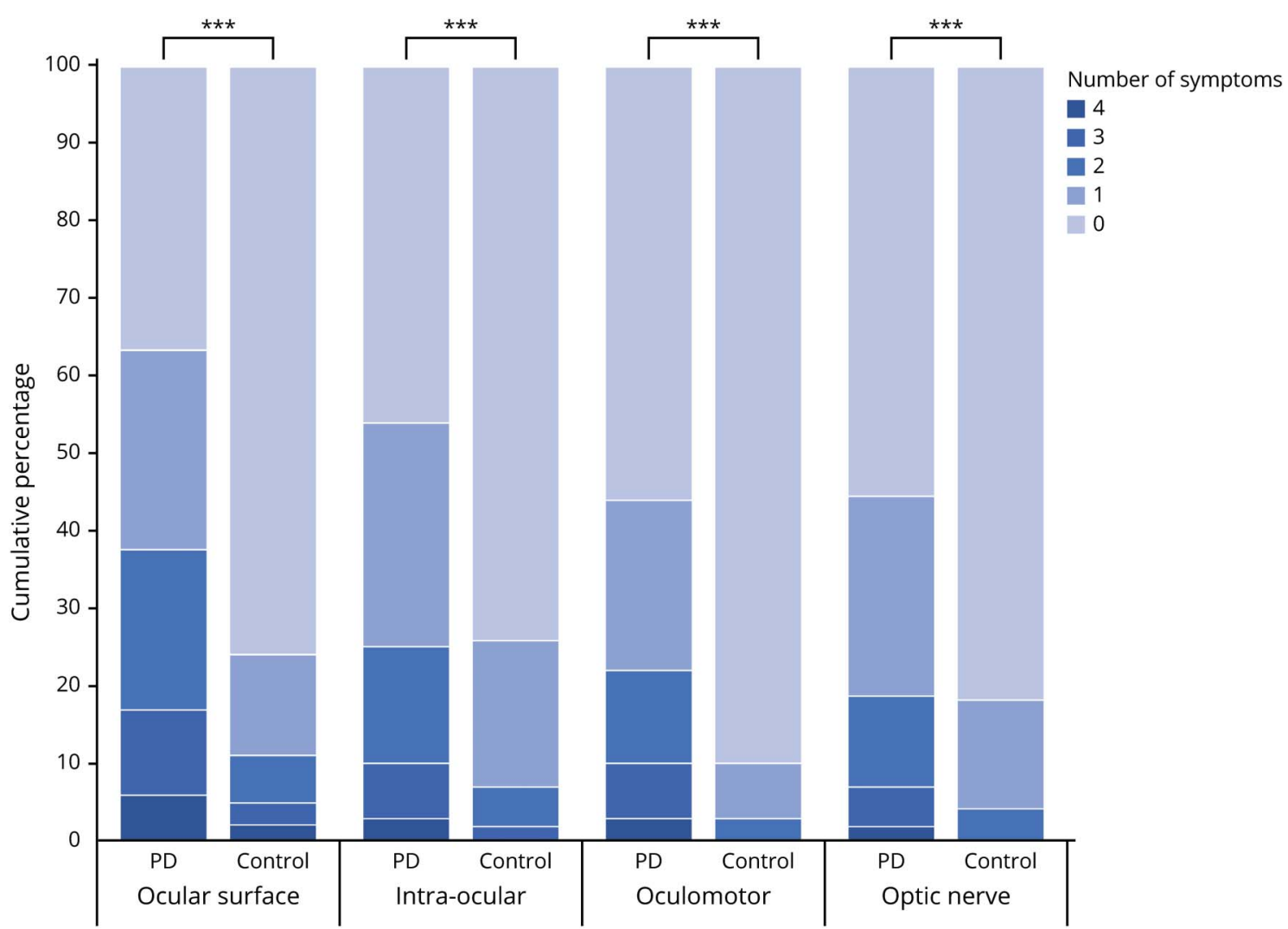

Each pair of bars represents patients with PD and healthy controls. The bars are divided into the cumulative percentages of participants reporting no ophthalmologic symptoms, 1 ophthalmologic symptom, 2 ophthalmologic symptoms, 3 ophthalmologic symptoms, or 4 ophthalmologic symptoms. For example, in the domain of the ophthalmologic surface, only $37 \%$ of the patients with PD reported no symptoms, compared with $76 \%$ in the control group. In the control group in the domains intraocular, oculomotor, and optic nerve the option " 4 symptoms" is $0 \%$. In the control group in the domains oculomotor and optic nerve the option "3 symptoms" is $0 \%$. *** $p<0.001$. 


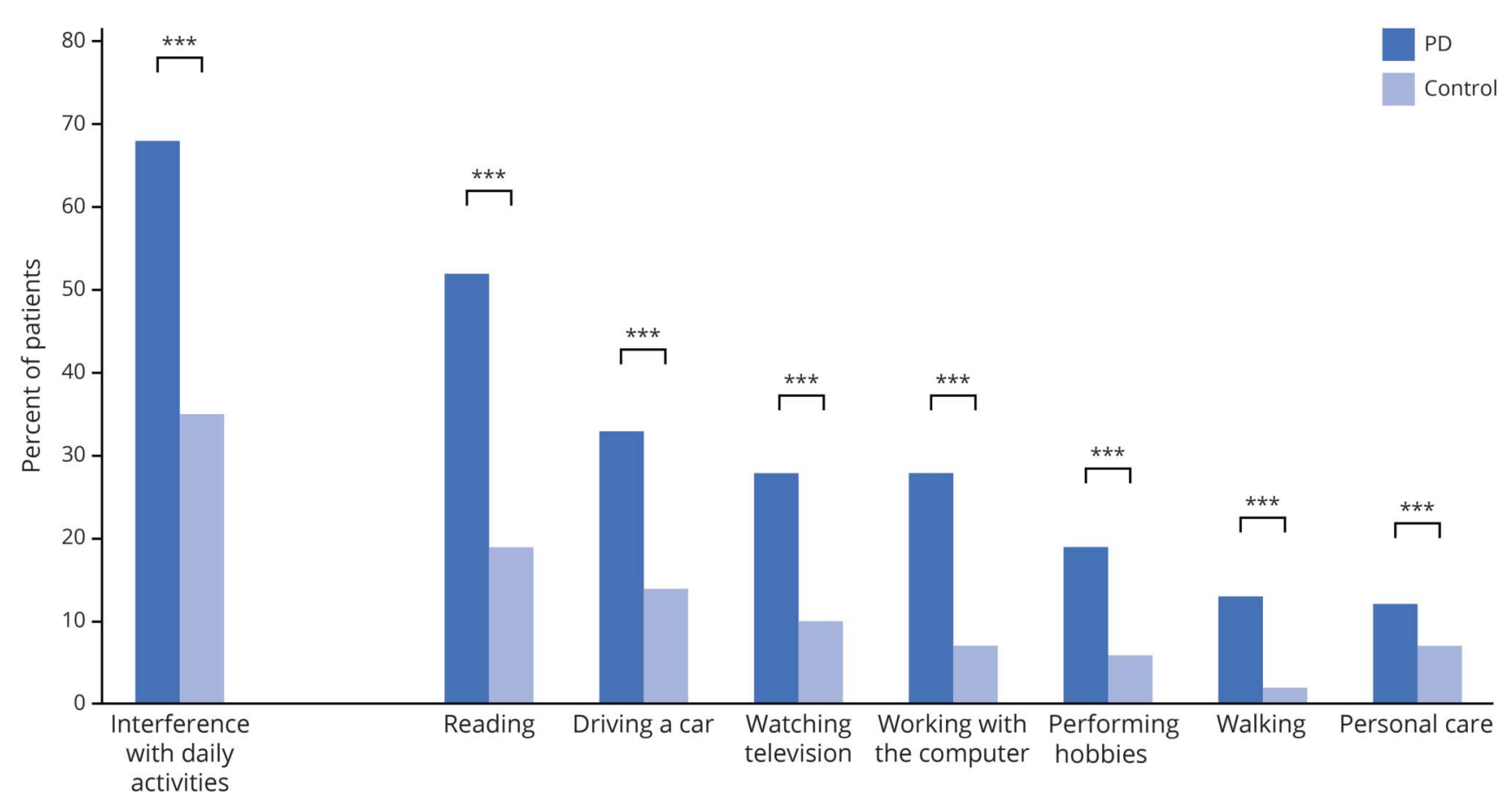

Reported interference with daily activities due to ophthalmologic symptoms in the Parkinson disease $(P D)$ group $(n=848)$ compared with controls $(n=250)$. Each pair of bars represents patients with PD compared with healthy controls. *** $p<0.001$.

\section{Internal consistency}

The internal consistency of the VIPD-Q was high with all 3 measurements for internal consistency: $\omega$ total 0.86 (95\% CI, $0.84-0.87$ ), greatest lower bound 0.86 , Cronbach coefficient $\alpha$ 0.86 (95\% CI, 0.84-0.87).

\section{Discussion}

In this study, we show that compared with controls, patients with PD have a higher prevalence of ophthalmologic symptoms, as reflected by a high VIPD-Q total score, suggesting that either PD itself or its treatment has an effect on ophthalmologic functions beyond the normal aging process. Moreover, ophthalmologic symptoms among patients with PD interfered with daily activities more frequently than in controls.

We showed that $82 \%$ of patients with PD reported at least 1 ophthalmologic symptom. This is higher than previously reported prevalence figures, which varied between $10 \%$ and $78 \%{ }^{3,9,10}$ Possible explanations for this discrepancy include the sample size (previous studies included only 10-100 participants) and the range of ophthalmologic symptoms that were studied. We included 848 patients and surveyed a very broad range of ophthalmologic symptoms and possible underlying ophthalmologic disorders. All investigated ophthalmologic symptoms were more common in patients with PD than controls. Alterations in the visual network from the retina to higher cortical brain regions have been found in PD, and may be the cause of ophthalmologic symptoms. ${ }^{26}$ As many as $63 \%$ of patients reported a problem in the ocular surface domain. In PD, the most common ocular surface disorder is dry eyes, which can cause decreased vision and contributes to reading difficulties. ${ }^{3,5}$ A significantly lower blink rate may lead to a less stable tear film by evaporation, causing dry eyes. This in turn may paradoxically lead to excessive blinking, watery eyes due to reflex tearing, and blepharospasm. ${ }^{3}$ Treatment of dry eyes with eyedrops is effective and has virtually no side effects. ${ }^{27}$ Treatments of other ocular surface disorders (e.g., blepharitis) are also noninvasive and may improve visual acuity. ${ }^{28,29}$ Although less frequent than among patients with $\mathrm{PD}$, ocular surface complaints were also common among controls (24\%), which is expected in an elderly population.,

Ophthalmologic symptoms in the intraocular and optic nerve domain were twice as frequent among patients with PD than controls. These symptoms are caused most commonly by cataract formation. This higher prevalence of symptoms possibly caused by cataract in patients with PD could result from the disease process of PD itself, since prominent $\alpha$-synuclein accumulation is present in residual lens fragments of patients with $\mathrm{PD} .^{31}$ Other possible contributing factors include deposition of abnormally phosphorylated $\alpha$-synuclein in the inner retinal layers, leading to retinal dopamine depletion and retinal dysfunction, or damage to the ganglion cell axons, leading to optic nerve head atrophy. ${ }^{31-35}$ Also, there 
may be a relationship between PD and neovascular macular degeneration. All these factors could cause changes in color and contrast vision, metamorphopsia, or impaired night vision. ${ }^{31-35}$ In our population, $26 \%$ of patients reported problems when reading a text on a colored or gray background, suggesting impaired contrast sensitivity, while $11 \%$ did not see colors as brightly as before, suggesting decreased color vision. This supports the association of impaired contrast sensitivity and decreased color vision with the neurodegenerative process in PD. ${ }^{15,36}$ Oculomotor symptoms were also frequently reported by patients with PD. Diplopia is a well-established nonmotor symptom in $\mathrm{PD} .{ }^{37}$ Oculomotor deficits in PD are thought to arise from deficits in oculomotor pathways in the brainstem, basal ganglia, and frontal lobes. Some may arise from dopamine depletion in the basal ganglia, causing excessive inhibition of the superior colliculus, which may lead to hypometric eye movements. ${ }^{38}$ In addition, cortical involvement in the disease process of PD may affect the cortical visual areas (including the frontal and parietal eye fields), which play an important role during the initiation of eye movements, anticipation of visual stimuli, target selection, and suppression of automatic responses to visual stimuli. ${ }^{38}$ As with many other ophthalmologic symptoms, patients with PD generally do not report diplopia spontaneously, hence treating physicians should actively ask for double vision and other ophthalmologic symptoms. ${ }^{39,40}$ In our study, $22 \%$ of patients reported visual hallucinations, compared with $30 \%-60 \%$ in previous studies. ${ }^{41}$ This discrepancy may be caused by underreporting of visual illusions-having the feeling that someone is in the room or interpreting a shadow as a person - which were part of earlier studies, but not explicitly surveyed by the VIPD-Q. Visual hallucinations may result from the disease process itself, as well as from its treatment. $^{21,42}$ Risk factors for visual hallucinations include ophthalmologic disorders, underlining the importance of recognizing ophthalmologic symptoms and starting early treatment when possible. ${ }^{21,43,44}$

We found a significant negative effect of ophthalmologic symptoms on daily activities and quality of life in patients with PD. The effect of ophthalmologic symptoms may be particularly vexing for patients with PD because of their need to compensate for their motor deficits by guiding their movements visually. This is reflected by the $22 \%$ of patients in this study who reported that ophthalmologic symptoms caused difficulties walking and performing hobbies. Also, patients with higher VIPD-Q scores reported more frequent falls. Visual deficits have frequently been associated with the postural instability and gait disorder phenotype, suggesting an association between the severity of ophthalmologic abnormalities and the severity of gait impairment. ${ }^{7,45,46}$ Furthermore, half of the patients experienced problems with reading. Reading difficulties may be caused by various ophthalmologic disorders (e.g., convergence insufficiency) as well as by concentration deficits. In this study, ophthalmologic symptoms interfered with driving a car among $33 \%$ of patients. Difficulties driving a car have been attributed to impaired contrast sensitivity and visual processing in PD. ${ }^{47,48}$
This is supported by our results, where $26 \%$ of patients experienced problems with contrast vision, $43 \%$ had difficulties driving at night, and $17 \%$ had problems with depth perception. Ophthalmologic symptoms fluctuated during the day in around one-third of patients and may have varied depending on the specific activities at hand; for instance, diplopia may arise only during reading caused by convergence insufficiency, or blurry vision may occur preferentially in a crowded place in patients with impaired visual processing. ${ }^{39,49,50}$

The observational nature of our study brings about some limitations. First, the sampling method may have led to a selection bias (patients with visual complaints being more likely to respond), potentially causing an overestimation of ophthalmologic symptoms. This selection bias may explain the higher total VIPD-Q score in patients with PD who participated through the open Web link compared with respondents by mail or interview. However, the patients selected in Innsbruck (where the risk of selection bias was low because of the inclusion procedure and high response rate) had an only slightly lower prevalence than what we found in the other sampling methods.

Furthermore, there is a potential self-report bias. This includes a self-report bias for the diagnosis of PD. Even in the hands of a neurologist, misclassification can be as high as $25 \%$ of cases, and the percentage might have been even higher here. We tried to minimize this by inviting patients registered with a diagnosis of PD that was established by a neurologist with dedicated experience in movement disorders in all 3 centers.

Another limitation is the unvalidated nature of our questionnaire. The correlation between the ophthalmologic symptoms reported in the VIPD-Q and actual ophthalmologic diseases has not yet been established and this will be the objective of future research. ${ }^{13}$ Nevertheless, the high prevalence of ophthalmologic symptoms and their effect on daily life is striking, and emphasizes the need to address this subject in both research and clinical practice. Patients who report ophthalmologic symptoms need a referral for further evaluation. For those patients who do not volunteer problems themselves, a screening questionnaire such as the VIPD-Q may help with identifying ophthalmologic symptoms in PD that might otherwise be missed, thereby enabling timely referral and treatment. Further work is needed to optimize the present VIPD-Q for such use in screening.

\section{Acknowledgment}

The authors thank the patients and their families for participation.

\section{Study funding}

This study is funded by a research grant from the Stichting Parkinson Fonds (grant 38000). The funding source had no role in the design and conduct of the study; collection, management, analysis, and interpretation of the data; preparation, review, or approval of the manuscript; or decision to 
submit the manuscript for publication. No compensation from a funding source was received.

\section{Disclosure}

C.D.J.M. Borm, F. Visser, M. Werkmann, D. De Graaf, D. Putz, K. Seppi, W. Poewe, A. Vlaar, and C. Hoyng report no disclosures relevant to the manuscript. B.R. Bloem reports grants from the Michael J. Fox Foundation, ZonMw, Stichting Parkinson Nederland, Parkinson Vereniging, Hersenstichting Nederland, Parkinson's Foundation, Verily Life Sciences, Horizon 2020, and Topsector Life Sciences and Health; grants and personal fees from UCB; and personal fees from AbbVie, Bial, and Zambon. T. Theelen and N.M. de Vries report no disclosures relevant to the manuscript. Go to Neurology.org/N for full disclosures.

\section{Publication history}

Received by Neurology July 18, 2019. Accepted in final form October 15, 2019.

\section{Appendix Authors}

\begin{tabular}{|c|c|c|c|}
\hline Name & Location & Role & Contribution \\
\hline $\begin{array}{l}\text { Carlijn } \\
\text { D.J.M. Borm, } \\
\text { MD }\end{array}$ & $\begin{array}{l}\text { Radboud University } \\
\text { Medical Centre, } \\
\text { Nijmegen, the } \\
\text { Netherlands }\end{array}$ & Author & $\begin{array}{l}\text { Designed and } \\
\text { conceptualized study, } \\
\text { major role in the } \\
\text { acquisition of data, } \\
\text { analyzed the data, } \\
\text { drafted the manuscript } \\
\text { for intellectual content }\end{array}$ \\
\hline
\end{tabular}

\begin{tabular}{lll}
\hline Femke & OLVG, Amsterdam, Author & Designed and \\
Visser, MD the Netherlands & conceptualized study, \\
& major role in the \\
& acquisition of data, \\
analyzed the data, & drafted the manuscript \\
& for intellectual content
\end{tabular}

\begin{tabular}{|c|c|c|c|}
\hline $\begin{array}{l}\text { Mario } \\
\text { Werkmann, } \\
\text { MD }\end{array}$ & $\begin{array}{l}\text { Medical University } \\
\text { Innsbruck, Austria }\end{array}$ & Author & $\begin{array}{l}\text { Designed and } \\
\text { conceptualized study, } \\
\text { major role in the } \\
\text { acquisition of data }\end{array}$ \\
\hline $\begin{array}{l}\text { Debbie de } \\
\text { Graaf, MSc }\end{array}$ & $\begin{array}{l}\text { Radboud University } \\
\text { Medical Centre, } \\
\text { Nijmegen, the } \\
\text { Netherlands }\end{array}$ & Author & $\begin{array}{l}\text { Major role in the } \\
\text { acquisition of data }\end{array}$ \\
\hline $\begin{array}{l}\text { Diana Putz, } \\
\text { MD }\end{array}$ & $\begin{array}{l}\text { Medical University } \\
\text { Innsbruck, Austria }\end{array}$ & Author & $\begin{array}{l}\text { Interpreted the data, } \\
\text { revised the manuscript } \\
\text { for intellectual content }\end{array}$ \\
\hline $\begin{array}{l}\text { Klaus Seppi, } \\
\text { MD }\end{array}$ & $\begin{array}{l}\text { Medical University } \\
\text { Innsbruck, Austria }\end{array}$ & Author & $\begin{array}{l}\text { Interpreted the data, } \\
\text { revised the manuscript } \\
\text { for intellectual content }\end{array}$ \\
\hline $\begin{array}{l}\text { Werner } \\
\text { Poewe, MD }\end{array}$ & $\begin{array}{l}\text { Medical University } \\
\text { Innsbruck, Austria }\end{array}$ & Author & $\begin{array}{l}\text { Interpreted the data, } \\
\text { revised the manuscript } \\
\text { for intellectual content }\end{array}$ \\
\hline $\begin{array}{l}\text { Annemarie } \\
\text { M.M. Vlaar, } \\
\text { MD, PhD }\end{array}$ & $\begin{array}{l}\text { OLVG, Amsterdam, } \\
\text { the Netherlands }\end{array}$ & Author & $\begin{array}{l}\text { Interpreted the data, } \\
\text { revised the manuscript } \\
\text { for intellectual content }\end{array}$ \\
\hline $\begin{array}{l}\text { Carel } \\
\text { Hoyng, MD, } \\
\text { PhD }\end{array}$ & $\begin{array}{l}\text { Radboud University } \\
\text { Medical Centre, } \\
\text { Nijmegen, the } \\
\text { Netherlands }\end{array}$ & Author & $\begin{array}{l}\text { Interpreted the data, } \\
\text { revised the manuscript } \\
\text { for intellectual content }\end{array}$ \\
\hline
\end{tabular}

Appendix (continued)

\begin{tabular}{|c|c|c|c|}
\hline Name & Location & Role & Contribution \\
\hline $\begin{array}{l}\text { Bastiaan R. } \\
\text { Bloem, MD, } \\
\text { PhD }\end{array}$ & $\begin{array}{l}\text { Radboud University } \\
\text { Medical Centre, } \\
\text { Nijmegen, the } \\
\text { Netherlands }\end{array}$ & Author & $\begin{array}{l}\text { Conceptualized study, } \\
\text { interpreted the data, } \\
\text { revised the manuscript } \\
\text { for intellectual content }\end{array}$ \\
\hline $\begin{array}{l}\text { Thomas } \\
\text { Theelen, } \\
\text { MD, PhD }\end{array}$ & $\begin{array}{l}\text { Radboud University } \\
\text { Medical Centre, } \\
\text { Nijmegen, the } \\
\text { Netherlands }\end{array}$ & Author & $\begin{array}{l}\text { Interpreted the data, } \\
\text { revised the manuscript } \\
\text { for intellectual content }\end{array}$ \\
\hline $\begin{array}{l}\text { Nienke M. } \\
\text { de Vries, } \\
\text { PhD }\end{array}$ & $\begin{array}{l}\text { Radboud University } \\
\text { Medical Centre, } \\
\text { Nijmegen, the } \\
\text { Netherlands }\end{array}$ & Author & $\begin{array}{l}\text { Interpreted the data, } \\
\text { revised the manuscript } \\
\text { for intellectual content }\end{array}$ \\
\hline
\end{tabular}

\section{References}

1. Ekker MS, Janssen S, Seppi K, et al. Ocular and visual disorders in Parkinson's disease: common but frequently overlooked. Parkinsonism Relat Disord 2017;40:1-10

2. Archibald NK, Clarke MP, Mosimann UP, Burn DJ. The retina in Parkinson's disease. Brain 2009; 132:1128-1145.

3. Biousse V, Skibell BC, Watts RL, Loupe DN, Drews-Botsch C, Newman NJ. Ophthalmologic features of Parkinson's disease. Neurology 2004;62:177-180.

4. Pascolini D, Mariotti SP. Global estimates of visual impairment: 2010. Br J Ophthalmol 2012;96:614-618.

5. Miljanovic B, Dana R, Sullivan DA, Schaumberg DA. Impact of dry eye syndrome on vision-related quality of life. Am J Ophthalmol 2007;143:409-415.

6. Amick MM, Grace J, Ott BR. Visual and cognitive predictors of driving safety in Parkinson's disease patients. Arch Clin Neuropsychol 2007;22:957-967.

7. Wood BH, Bilclough JA, Bowron A, Walker RW. Incidence and prediction of falls in Parkinson's disease: a prospective multidisciplinary study. J Neurol Neurosurg Psychiatry 2002;72:721-725.

8. Azulay JP, Mesure S, Amblard B, Pouget J. Increased visual dependence in Parkinson's disease. Perceptual Mot Skills 2002;95:1106-1114.

9. McDowell SA, Harris JP. Visual problems in Parkinson's disease: a questionnaire survey. Behav Neurol 1997;10:77-81.

10. Urwyler P, Nef T, Killen A, et al. Visual complaints and visual hallucinations in Parkinson's disease. Parkinsonism Relat Disord 2014;20:318-322.

11. Davidsdottir S, Cronin-Golomb A, Lee A. Visual and spatial symptoms in Parkinson's disease. Vis Res 2005;45:1285-1296.

12. Sauerbier A, Ray Chaudhuri K. Parkinson's disease and vision. Basal Ganglia 2013;3: 159-163.

13. Borm C, Werkmann M, Visser F, et al. Towards seeing the visual impairments in Parkinson's disease: protocol for a multicentre observational, cross-sectional study. BMC Neurol 2019;19:141.

14. Nowacka B, Lubinski W, Honczarenko K, Potemkowski A, Safranow K. Ophthal mological features of Parkinson disease. Med Sci Monit 2014;20:2243-2249.

15. Muller T, Kuhn W, Buttner T, Przuntek H. Distorted colour discrimination in Parkinson's disease is related to severity of the disease. Acta Neurol Scand 1997;96: 293-296.

16. Pieri V, Diederich NJ, Raman R, Goetz CG. Decreased color discrimination and contrast sensitivity in Parkinson's disease. J Neurol Sci 2000;172:7-11.

17. Hutton JT, Morris JL. Vision in Parkinson's disease. Adv Neurol 2001;86:279-288.

18. Muller T, Woitalla D, Peters S, Kohla K, Przuntek H. Progress of visual dysfunction in Parkinson's disease. Acta Neurol Scand 2002;105:256-260.

19. Tamer C, Melek IM, Duman T, Oksuz H. Tear film tests in Parkinson's disease patients. Ophthalmology 2005;112:1795.

20. Matsui H, Udaka F, Tamura A, et al. Impaired visual acuity as a risk factor for visual hallucinations in Parkinson's disease. J Geriatr Psychiatry Neurol 2006;19:36-40.

21. Diederich NJ, Fenelon G, Stebbins G, Goetz CG. Hallucinations in Parkinson disease. Nat Rev Neurol 2009;5:331-342.

22. Seichepine DR, Neargarder S, Miller IN, Riedel TM, Gilmore GC, Cronin-Golomb A Relation of Parkinson's disease subtypes to visual activities of daily living. J Int Neuropsychol Soc 2011;17:841-852.

23. Armstrong RA. Oculo-visual dysfunction in Parkinson's disease. J Parkinsons Dis 2015;5:715-726.

24. Lin TP, Rigby H, Adler JS, et al. Abnormal visual contrast acuity in Parkinson's disease. J Parkinsons Dis 2015;5:125-130.

25. Matlach J, Wagner M, Malzahn U, et al. Retinal changes in Parkinson's disease and glaucoma. Parkinsonism Relat Disord 2018;56:41-46.

26. Weil RS, Schrag AE, Warren JD, Crutch SJ, Lees AJ, Morris HR. Visual dysfunction in Parkinson's disease. Brain 2016;139:2827-2843.

27. Huang FC, Tseng SH, Shih MH, Chen FK. Effect of artificial tears on corneal surface regularity, contrast sensitivity, and glare disability in dry eyes. Ophthalmology 2002; 109:1934-1940 
28. The management of dry eye. BMJ 2016;353:i2333.

29. Milner MS, Beckman KA, Luchs JI, et al. Dysfunctional tear syndrome: dry eye disease and associated tear film disorders: new strategies for diagnosis and treatment. Curr Opin Ophthalmol 2017;27(suppl 1):3-47.

30. Ding J, Sullivan DA. Aging and dry eye disease. Exp Gerontol 2012;47:483-490.

31. Klettner A, Richert E, Kuhlenbaumer G, et al. Alpha synuclein and crystallin expression in human lens in Parkinson's disease. Mov Disord 2016;31:600-601.

32. Ortuno-Lizaran I, Beach TG, Serrano GE, Walker DG, Adler CH, Cuenca N. Phosphorylated alpha-synuclein in the retina is a biomarker of Parkinson's disease pathology severity. Mov Disord 2018;33:1315-1324.

33. Chung SD, Ho JD, Hu CC, Lin HC, Sheu JJ. Increased risk of Parkinson disease following a diagnosis of neovascular age-related macular degeneration: a retrospective cohort study. Am J Ophthalmol 2014;157:464-469.e461.

34. Etminan M, Samii A, He B. Risk of Parkinson's disease in patients with neovascular age-related macular degeneration. J Curr Ophthalmol 2018;30:365-367.

35. Yenice O, Onal S, Midi I, Ozcan E, Temel A, I-Gunal D. Visual field analysis in patients with Parkinson's disease. Parkinsonism Relat Disord 2008;14:193-198.

36. Guo L, Normando EM, Shah PA, De Groef L, Cordeiro MF. Oculo-visual abnormalities in Parkinson's disease: possible value as biomarkers. Mov Disord 2018;33: 1390-1406.

37. Chaudhuri KR, Martinez-Martin P, Schapira AH, et al. International multicenter pilot study of the first comprehensive self-completed nonmotor symptoms questionnaire for Parkinson's disease: the NMSQuest study. Mov Disord 2006;21: 916-923.

38. Terao Y, Fukuda H, Ugawa Y, Hikosaka O. New perspectives on the pathophysiology of Parkinson's disease as assessed by saccade performance: a clinical review. Clin Neurophysiol 2013;124:1491-1506.
39. Barrell K, Bureau B, Turcano P, et al. High-order visual processing, visual symptoms, and visual hallucinations: a possible symptomatic progression of Parkinson's disease. Front Neurol 2018;9:999.

40. Visser F, Vlaar AMM, Borm C, et al. Diplopia in Parkinson's disease: visual illusion or oculomotor impairment? J Neurol 2019;266:2457-2464.

41. Goetz CG, Leurgans S, Pappert EJ, Raman R, Stemer AB. Prospective longitudinal assessment of hallucinations in Parkinson's disease. Neurology 2001;57:2078-2082.

42. Ffytche DH, Blom JD, Catani M. Disorders of visual perception. J Neurol Neurosurg Psychiatry 2010;81:1280-1287.

43. Aarsland D, Larsen JP, Tandberg E, Laake K. Predictors of nursing home placement in Parkinson's disease: a population-based, prospective study. J Am Geriatr Soc 2000;48: 938-942.

44. Archibald NK, Clarke MP, Mosimann UP, Burn DJ. Visual symptoms in Parkinson's disease and Parkinson's disease dementia. Mov Disord 2011;26:2387-2395.

45. Caudron S, Guerraz M, Eusebio A, Gros JP, Azulay JP, Vaugoyeau M. Evaluation of a visual biofeedback on the postural control in Parkinson's disease. Neurophysiol Clin 2014;44:77-86.

46. Ivers RQ, Cumming RG, Mitchell P, Attebo K. Visual impairment and falls in older adults: the blue mountains eye study. J Am Geriatr Soc 1998;46:58-64.

47. Uc EY, Rizzo M, Anderson SW, Sparks J, Rodnitzky RL, Dawson JD. Impaired visual search in drivers with Parkinson's disease. Ann Neurol 2006;60:407-413.

48. Worringham CJ, Wood JM, Kerr GK, Silburn PA. Predictors of driving assessment outcome in Parkinson's disease. Mov Disord 2006;21:230-235.

49. Diederich NJ, Raman R, Leurgans S, Goetz CG. Progressive worsening of spatial and chromatic processing deficits in Parkinson disease. Arch Neurol 2002;59:1249-1252.

50. Law C, Chriqui E, Kergoat MJ, et al. Prevalence of convergence insufficiency-type symptomatology in Parkinson's disease. Can J Neurol Sci 2017;44:562-566. 


\section{Neurology}

\section{Seeing ophthalmologic problems in Parkinson disease: Results of a visual impairment questionnaire}

Carlijn D.J.M. Borm, Femke Visser, Mario Werkmann, et al.

Neurology 2020;94;e1539-e1547 Published Online before print March 11, 2020

DOI 10.1212/WNL.0000000000009214

\section{This information is current as of March 11, 2020}

\section{Updated Information \&} Services

References

Subspecialty Collections

Permissions \& Licensing

Reprints including high resolution figures, can be found at: http://n.neurology.org/content/94/14/e1539.full

This article cites 50 articles, 6 of which you can access for free at: http://n.neurology.org/content/94/14/e1539.full\#ref-list-1

This article, along with others on similar topics, appears in the following collection(s):

All Neuro-ophthalmology

http://n.neurology.org/cgi/collection/all_neuroophthalmology

Parkinson's disease/Parkinsonism

http://n.neurology.org/cgi/collection/parkinsons_disease_parkinsonism Prevalence studies

http://n.neurology.org/cgi/collection/prevalence_studies

Information about reproducing this article in parts (figures,tables) or in its entirety can be found online at:

http://www.neurology.org/about/about_the_journal\#permissions

Information about ordering reprints can be found online:

http://n.neurology.org/subscribers/advertise

Neurology ${ }^{\circledR}$ is the official journal of the American Academy of Neurology. Published continuously since 1951, it is now a weekly with 48 issues per year. Copyright Copyright (C) 2020 The Author(s). Published by Wolters Kluwer Health, Inc. on behalf of the American Academy of Neurology.. All rights reserved. Print ISSN: 0028-3878. Online ISSN: 1526-632X.

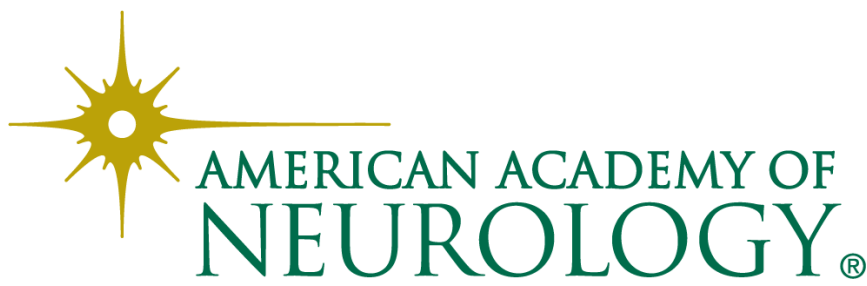

